\title{
I can see you! Using Videos in Online Courses to Promote Student Engagement
}

\begin{abstract}
Alison B. Oberne ${ }^{1}$
Abstract: Universities worldwide engage students through online learning. One challenge is the ability to promote a community of learners in an online classroom. Faculty teaching online courses can include student video discussion posts to promote engagement and the development of an online student community. Faculty integrate student video posts into graded, online discussion board assignments. Students record and upload videos into online discussion board forums and then respond to one another's videos using text-based discussion posts. There are benefits and challenges to this teaching method. Having a strong technical support staff can ease the use of video discussion posts in online courses. Overall, video discussion posts promote a sense of community in online courses.
\end{abstract}

Keywords: teaching, online, video, discussion boards.

Universities worldwide engage students through online learning. One challenge is the ability to promote a community of learners in an online classroom. Often students lack a strong sense of cohesion when enrolled in online courses (Luo, 2011; Peters, 2001). One effort to promote an online community is through instructor-delivered videos. Instructors often post introductory or weekly videos to engage their students in online courses. The provision of instructor-based videos helps to establish instructor teaching presence and improve student attitudes (Draus, Curran, \& Trempus, 2014; Miller \& Redman, 2010). However, this does not promote student interactivity or collaboration.

One way to promote student interactivity in online courses is through discussions or collaboration sessions. Many Learning Management Systems (LMS) include video communication tools that facilitate these collaborations. For example, BlackBoard has a Collaborate tool within the system that allows students and faculty to interact with one another in a synchronous fashion. These sessions can promote interactivity, however, they require all participants to attend the session at the same time. This can pose a problem for courses that do not require synchronous collaborations. Asynchronous courses can be advantageous for students who have multiple demands, including other courses and work, or who live in other time zones than the host institution.

Faculty often use student discussion boards in asynchronous online courses to facilitate learning. Typically, online discussion boards have specific requirements, including quantity and quality of posts, and are a part of the course grades (Bliss \& Lawrence, 2009). Discussion boards aim to promote a sense of community among students. However, students often lack the benefit of interaction often gleaned in classroom-based courses. To promote student engagement and a sense of community, video posts can be incorporated into online courses. Video posts allow students to learn from one another using oral communication strategies. Online courses usually promote written communication, however, additional communication strategies can encourage student skill-building.

\footnotetext{
${ }^{1}$ Office of Undergraduate Studies, College of Public Health, University of South Florida, 13201 Bruce B. Downs Blvd MDC 56, Tampa, FL 33612, aoberne@ health.usf.edu.
} 
The goal of this teaching methods paper is to describe how to incorporate student video posts into graded, online discussion board assignments. Student video posts foster online community and promote oral communication skills in online courses.

\section{Teaching method}

This teaching method is designed for online courses, in any discipline, including undergraduate or graduate courses. Instructors can modify existing graded discussion assignments or develop new graded discussion assignments to include student video posts. In online classes, students often submit multiple posts within one discussion assignment. The goal of this assessment strategy is for students to submit the video post as the first a series of posts. For example, students may be required to submit 3 posts in each graded discussion. Students record videos to fulfill the first post and submit text-based response posts for the second and third posts.

Video posts should include specific requirements, similar to text-based posts. Students must include each criterion in their videos in order to earn credit. In addition, students earn points for completing video posts instead of text based posts (See Sample Assignment Description and Grading Rubric in the Appendix). Instructors can designate specific requirements including length of video, video content, and professionalism as a part of the assignment rubric.

To facilitate the use of video posts, it is recommended that instructors indicate the use of video-based discussion boards in their course description. Students can use this information when registering for courses. In addition, this allows students ample time to access tools for completing video posts. Students who choose to enroll in the course, but who do not submit video posts, can still complete the course successfully. They will, however, receive point deductions for not adhering to the video post formatting requirement (See Grading Rubric in the Appendix).

One week prior to the submission of the first video post, it is recommended for the instructor to post a sample video. The sample video should include all required components so students can understand how to complete their videos. In addition, very detailed written descriptions should be provided so students can complete this assignment with success. Additionally, a benefit of including multiple discussions within a course is that students can improve their grades with each submission based on instructor feedback.

The following describes in detail how to set up video posts within course discussions. First, students record videos fulfilling assignment requirements. Videos can be created using a variety of technology devices including computers or tablets with built-in cameras, computers or tablets with external webcams, or smart phones. Second, students upload their videos into discussion board forums. Some LMS, such as Canvas, have features where students can create and post videos directly within discussion boards. Other students may opt to post videos after saving as a file on their computers or uploading onto YouTube and then submitting the link to the discussion board.

Third, students respond to one another's videos using text-based posts. These text-based posts are similar to traditional posts and can include specific criteria designated by each instructor. I recommend having students respond to multiple video posts so students can interact with one another and broaden their online learning network. For example, text-based posts can describe how students agree or disagree with content provided in the video posts. 


\section{Results}

This teaching method has been fully integrated into one undergraduate course for the past two semesters. Over 80 students have participated in this course. All students enrolled in this course are undergraduate students who selected the course as an option from a list of required courses in completion of their Bachelor's degree. Both formal and informal evaluation data has been collected to better understand student perceptions of video-based posts. The following benefits and limitations are based on informal mid-term evaluation data and formal end of the semester course evaluation data collected to better understand student perceptions of video-based posts.

\section{Benefits}

Video posts facilitate student connectivity. This is evidenced through students' online interactions. Students engage one another by name and actively comment about student content in video posts. For example, several students commented that "you can interact with others in this course in a fun and creative way", they can "engage and connect more with [their] peers", and they can see their "classmates because this doesn't usually happen in an online class". In addition, students continue to build this sense of community throughout the semester as they continue to submit and respond to video posts.

\section{Limitations}

Although there are many benefits associated with this teaching strategy, there are some challenges. One challenge students experienced was recording videos. Some students had never endeavored to record videos. So, they needed to familiarize themselves with the technology prior to completing the assignment. Another challenge is lack of familiarity with submitting videos to discussion board forums. One student commented that videos may take up to one hour to submit. Therefore, describing in detail the submission process can help students have realistic expectations for this assignment. Also, having support staff for online courses can help ease the creation and submission process and provide technical assistance to students.

One additional challenge is apprehension regarding public speaking. Many students lack confidence in public speaking and were afraid to record video posts. Requiring video posts can help students overcome their insecurities by building comfort with public speaking. Students submit posts to a small group of their peers so they can engage with one another in a safe, online environment.

\section{Conclusions}

Integrating video posts into online course discussions support oral communication skills, student engagement, and a sense of community otherwise absent in online courses. The implementation of this teaching method promotes a well-rounded learning environment and continues to foster innovation in online learning. 


\section{Appendix \\ Appendix 1. Sample Assignment Description and Grading Rubric}

\section{Technical Requirements:}

- Number of posts: You must submit 3 posts.

- Discussion Post 1: Video post.

- Discussion Posts 2 \& 3: Text-based replies to two different videos

First Post Requirements:

- First posts will take the form of a video. The goal is to imagine you have just left the movie theatre and are being asked to react to the public health impact of this movie. The video should be conversational and does not need to be a perfect speech. In fact, I don't recommend writing a speech to read but it is often helpful for students to jot some notes and have some plans of what to cover.

- Describe in detail one connection between the movie and public health. Be sure that your discussion is unique and not similar to a connection already made by a peer. This discussion can reflect an overall connection between public health and the movie. It can also highlight a specific scene, character, part of the plot, etc. The discussion should include specific examples from the movie to support the connection.

- This post should also include your "movie rating". Rate the movie on a scale of 1 (utter waste of time) to 10 (ready to watch again and again) and describe your reason for this rating.

- Do not give a summary of the movie. All students are watching and commenting on the same movie.

- In the past, students have asked for general guidelines for video length. My recommendation is to have a video post between 2 and 5 minutes in length. This time frame should be sufficient for covering the issues and not feel too challenging.

\section{Posts $2 \& 3$ Requirements:}

- Students will complete 2 reply posts. These are two text-based posts to any two video posts of your peers.

- Students can include the following types of information in the reply posts: 1) agreements or disagreements to the person's observations or 2) additional insights/connections not mentioned in the person's video.

- Each reply post must be a minimum of 100 words.

Grading point structure

5 points - Number of posts

- 0 points - Submitted 1 post

- 2.5 points - Submitted 2 posts 
- 5 points - Submitted 3 or more posts

5 points - First post: Video submission

- 0 points - First post is not submitted in video format

- 5 points - First post is submitted in video format

10 points - First post public health connection

- 0 points - the public health connection was not original OR the student merely offered a summary of the movie with no in-depth public health connection

- 5 points - student made an original connection between public health and the movie but the discussion was lacking in detail and needed more examples to solidify a connection.

- 10 points - student made an original connection between public health and the movie. The discussion was detailed and included specific examples from the movie.

5 points - First post movie rating

- 0 points -student did not give a movie rating.

- 2.5 points - student gave a movie rating but did not include a rationale to support the rating.

- 5 points - student gave a movie rating and included a rationale to support the rating.

5 points - Reply posts: Length

- 0 points - Both reply posts are less than 100 words in length

- 2.5 points -1 reply post is less than 100 words in length

- 5 points - All reply posts are at least 100 words in length

10 points - Reply posts: Content

- 0 points - absent OR both replies were incomplete and lacked substance.

- 5 points - student completely replied to 1 video post and offered either: 1) agreement or disagreement OR 2) additional insights/connections not mentioned in the videos BUT one reply was lacking substance. For example, including at least 100 words for each post but less than 100 words was devoted to the public health connection.

- 10 points - student completely replied to 2 video posts and offered either: 1) agreement or disagreement OR 2) additional insights/connections not mentioned in the videos.

\section{References}

Bliss, C. A., \& Lawrence, B. (2009). From posts to patterns: A metric to characterize discussion board activity in online courses. Journal of Asynchronous Learning Networks, 12(2), 15-32.

Draus, P. J., Curran, M. J., \& Trempus, M. S. (2014). The influence of instructor-generated video content on student satisfaction with and engagement in asynchronous online classes. Journal of Online Learning and Teaching, 10(2), 240-54. 
Luo, T. (2011). An exploratory study of students' perception of their online learning experiences in a Midwestern university. Retrieved December 20, 2015, from

http://digitalcommons.odu.edu/cgi/viewcontent.cgi?article=1020\&context=teachinglearning fac _pubs

Miller, S. T. \& Redman, S. L. (2010). Improving instructor presence in an online introductory astronomy course through video demonstrations. Astronomy Education Review, 9(1). Doi: 10.3847/AER2009042.

Peters, L. (2001). Through the looking glass: Student perceptions of online learning. Retrieved December 20, 2015, from http://technologysource.org/article/through_the_looking_glass/ 